\title{
Stimulatory Influence of select Spices on Gastric Acid Secretion in Anaesthetized Wistar Rats
}

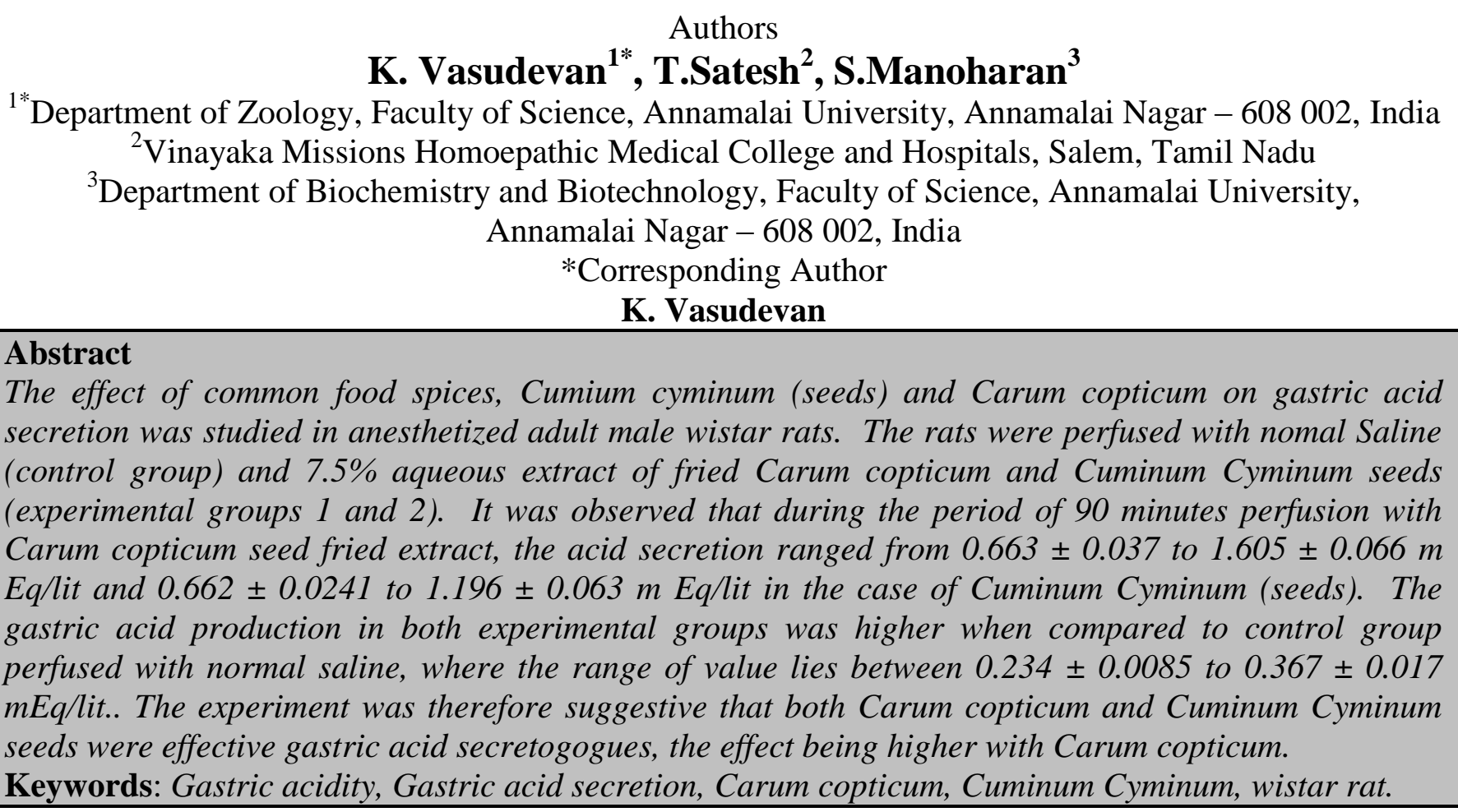

\section{Introduction}

Spices are considered as an important additive to food in several parts of the world. They enhance aroma, piquancy, and impart flavor to food. For long, they have been regarded as the essential component of eastern cuisine and have also been adopted into western diets. Since ancient times, spices and herbs have also been used in traditional treatment of a number of diseases Nowadays, several experimental studies and, to a lesser extent, clinical trials have also emphasized the role of food spices in the treatment of a variety of disorders (Chelladurai, 1991; Nadkarni and Nadkarni, ${ }^{(8)}$ 1976; Almofleh, ${ }^{(1)}$ 2010, Patel and
Srinivasan, 2001; 2004 Ikwebe Joseph, 2017; Liszt, 2017) ${ }^{(7)}$ Several spices and herbal extracts have been shown to Food spices are invariably used in the Indian cuisine. The spices are also used in the indigenous system of Indian Medicine (Nadkarni, 1976). Extracts of Carum copticum (Omum) and Cuminum Cyminum (cumin) seeds have been extensively used in Indian medicine (Kirtikar and Basu, 1984). ${ }^{(6)}$ In rats gastric mucosal protecting effect, anticholinergic, antioxidant effects of Feruala assa foedia reported (Begheri et al; 2018. The effect of orally ingested Capsicum peppers, ginger, garlic and piper pepper were stimulated gastric acid secretion in wistar 
rats (Ikwebe Joseph et.al.2017). The seeds of Carum copticum (L.) (Family: Apiaceae) locally known as Ajowan and Nakhwa; in the Middle East, and is primarily grown and used in the Indian subcontinent, and many other countries as a spice, flavoring agent and a condiment. Raw ajowan smells almost exactly like thyme, because it also contains thymol (Reynolds, 1989). ${ }^{(9)}$ Ajowan is being used as a carminative medicine from the ancient times, even Greek physicians used ajowan as carminative. The seeds are used as a medicament in Unani, Ayurvedic and Indian traditional medicine for its diuretic, analgesic, antiasthmatic, anthelmintic and antispasmodic properties (Nadkarni,1976). The ajowan has also been mentioned to have therapeutic effect on flatulence, indigestion, colic and dyspepsia (Kirtikar and Basu1984). Spices on gastric acid secretion and variations in gastric juice PHs reported in wistar rats (Ikwebe Joseph,2017); Caffeine induces gastric acid secretion via bitter taste signaling in gastric parietal cells (Liszt et al., 2017).

Aqueous extract of roasted seeds of Carum copticum has cholinomimetic effects (Devasankaraiah et al. 1974). ${ }^{(2)}$ Haranath et al. (1987) reported the presence of cholinomimetic components in common food spices. It posses carminative, stimulant properties. Cuminum Cyminum largely used as a spice in pickles. Cuminum cyminum seeds are used in Indian medicine for the control of chronic diarrheas. Both Carum copticum and Cuminum Cyminum seeds have been extensively used in indigenous medicine. Cuminum Cyminum seeds are used in Indian Cuisine. Extracts of Carum copticum are used in Indian households for therapeutic uses related to flatulence and related disorders. While these two spices are used in indigenous medicine, their precise function, as gastric acid secretogogue has not been studied extensively. In the present study investigates the effects of aqoeus extracts of Carum copticum and Cuminum cyminum on gastric acid secretion (GAS) in wistar albino rats.

\section{Materials and Methods \\ Spices Collection}

Fresh spices of Carum copticum, Cuminum cyminum were obtained from open market of Agricultural departmental stores in Chidambaram, Tamil Nadu, India and were washed properly, dried prior to use for preparation of extracts.

\section{Preparation of Spice Extract}

$2 \mathrm{gm}$ of spice is fried until slight fumes begin to appear, $20 \mathrm{ml}$ of distilled water is added to it and heating is discontinued. The mixture was allowed to cool for $60 \mathrm{~min}$. in the open. It is then filtered through watman No.1 filter paper. The extract is diluted by adding $10 \mathrm{ml}$ of water, and then used for perfusion studies.

\section{The Experimental Animals}

The animal welfare committee of our institution approved this study.18 Male adult wistar rats (weighing between $170 \mathrm{gm}$ to $200 \mathrm{gm}$ ) bred in the Department of Experimental Medicine, Central Animal House, Faculty of Medicine of Annamalai University were used for this study. The animals were housed under standard laboratory conditions and fed with standard lab animal feed (Hindustan lever Ltd., feeds, Bangalore) animals were provided with water ad libitum, but feeds given was regulated during spice extract administration period. Ethical regulations were adhered in accordance with standard guidelines for the protection animals' welfare during experimental process.

\section{Experimental Design}

The eighteen rats were rats divided in to three groups of six rats each (table 1) the animals were acclimatized for three weeks prior to the commencement of the study.

\section{Experimental Procedures}

The rats after an overnight fast were anaesthetized with pentobarbitone sodium ( $45 \mathrm{mg} / \mathrm{kg}$ ) given i.p. The rats were divided into three groups, control rats six nos received normal saline. Treatment 
groups each six rats received fried extracts of Carum copticum (CCE) and Cuminum Cyminum(CUE).

The anaesthetized rat was fixed to an operation board by using pins in a supine position. The neck was opened by a mid-line incision and trachea was cannulated with a polyethylene tube to administer artificial ventilation if necessary (Ghosh and Schild, 1958). ${ }^{(3)}$

A pediatric feeding catheter of $50 \mathrm{~cm}$ length (Romson-FG5) with a rounded end and with a side hole was introduced in to the esophagus to reach the stomach. This catheter is legated with the esophagus to prevent the backward pressure exerted by the fluid during perfusion. Through this tube the fluid is introduced into the stomach.

In the first part of duodenum another polyethylene cannulla is introduced into stomach and ligated at the pyloroduodinal junction. This is to drain the sample from the stomach for analysis. This is ligated using G-clamp to avoid the fluid escape and to collect gastric perfusion from the stomach.

\section{Perfusion Technique}

At the beginning of the experiment the stomach was washed thrice with $5 \mathrm{ml}$ of $0.9 \% \mathrm{NaCl}$ (NS) each time and any residual matter in the stomach was completely flushed out. No obstruction of the outflow cannula is observed in any of the experiments.

Attaching a $10 \mathrm{ml}$ syringe to the esophageal catheter formed the reservoir for perfusion fluid. Now, the duodenal cannula was calmped to make the perfusion fluid to stay in the stomach for required time adopted, modified method of Ghosh and Schild (1958).

Now $1.5 \mathrm{ml}$ of the perfusion fluid was pushed into the stomach through the esophageal catheter and the fluid was allowed to stay in the stomach for 15 min the fluid already present there will escapes through the duodenal cannula which was collected as the samples for analysis procedure adopted with modification. (Ghosh and Schild, 1958)

The perfusate samples were collected for every 15 mins and were labeled as $\mathrm{S}_{1}, \mathrm{~S}_{2, \ldots .} \mathrm{S}_{6}$ and their acidity was estimated by titrating against $0.002 \mathrm{~N}$ $\mathrm{NaOH}$ using Topfer's reagent as an indicator for estimating free acid and phenolphthalein as an indicator for estimating total acid. A pH METER (Digital, Global DPH-500) also determined the $\mathrm{pH}$ of the perfusate.

\section{Statistical Analysis}

Student's t-test for paired data was used for comparing means an appropriate. The values given are mean \pm Standard error

\section{Results and Discussion}

The experimental animals were fed and given water ad libitum. They were not provided feed for twelve hours before start of experiments. This was to ensure the rats were hungry during administration of extracts to achieve maximum efficacy of the dose.

\section{Gastric Acid Concentration}

The gastric acid concentration was determined from volume of base $(0.002 \mathrm{~N} \mathrm{NaOH})$ used in the titration of acid. Table 1 shows the effect of aquoes extracts of the spices on gastric acid secretion of the perfused sambles. The result indicate normal saline and aqueous extracts of Cuminum cyminum and Carum copticum on gastric acid secretion.

In experiments only with normal saline per fused, Gastric acid secretion showed gradual increase from $S_{1}-S_{3}$ from $0.234 \pm 0.0085$ to $0.303 \mathrm{mEq} / \mathrm{lit}$ $\pm 0.017 \mathrm{mEq} / \mathrm{lit}$ and the gastric acid secretion declined from $0.367 \pm 0.017$ in $\mathrm{S}_{3}$ to $0.214 \pm$ $0.0874 \mathrm{mEq} /$ lit in $\mathrm{S}_{6}$ (Table 1$)$.

In six experiments with only Carum copticum fried extract perfused throughout, the acid secretion progressively increase from $0.663 \pm$ $0.037 \mathrm{mEq} / \mathrm{lit}$ in $S_{1}$ to $1.605 \pm 0.066 \mathrm{mEq} / \mathrm{lit}$ in $\mathrm{S}_{5}(75 \mathrm{~min})$. Similar increase was observed with Cuminum Cyminum extract from $0.462 \pm 0.241$ in $\mathrm{S}_{1}$ to $1.196 \pm 0.063$ in $\mathrm{S}_{3}$ to $0.366 \pm 0.051 \mathrm{mEq} / \mathrm{lit}$ in $\mathrm{S}_{6}$ (Table 1).

In our study, intragastric perfusion of fried spice extracts in anaesthetized rats produced significant, 
reproducible increase in gastric acid secretion. Devasankaraiah et al. (1974) and Haranath et al., (1987) have observed maximum cholinergic activity, only with fried spice extracts and proved the presence of acetylcholine and choline in seeds of coriander, Cumin, Fennel, Red peppers and block peppers. Therefore, the present experiments have been performed with the extracts of fried spice seeds only on gastric acid secretion. The spice extracts follows extorts stimulation of submucous plexus neurons, which innervates secretary cells, via important bioactive molecules, fried spice extracts contain enormous, cholinergic compounds, responsible for increase in acid secretion in anesthetized rat (Haranth et al., 1987; ${ }^{(4)}$ Ikwebe Joseph et al., 2017). ${ }^{(5)}$ Gastric secretion at gastric phase efferent vagal pathway synapse with submucous plexus neurons, which innervate secretary cells, via important bioactive molecules responsible for gastric secretion (Camilleri and Vazquez Roque, 2014). Meyers et al (1987) have reported deleterious effects of red papper and black papper enhanced a significant enhancement in parietal secretion and gastric cell exfoliatio, which are comparable to those induced by aspirin. Some spices may stimulate acid secretion and have deleterious effects on the gastric mucosal lining. Intragastric perfusion of albino rats with aqueous extracts of red papper, fennel, omum, cardamom, black papper and coriander have stimulated a cholinergic response or via other mechanisms) have induced gastric acid secretion (Vasudevan et al., 2000; Mofleh, I.A.A, 2010).

In this investigation the results indicate that Carum copticum and Cuminum Cyminum are gastric stimulants produced significant reproducible increase in acid gastric secretion Extracts of Carum copticum and Cuminum Cyminum elicited 68 percent (S5) and 40 percent (S4) of gastric acid secretion over control respectively (Table 1).

\section{Gastric juice pH}

The pHs of the gastric perfusates of various rats were determined. The $\mathrm{pH}$ of various samples of perfusates were acidic, ranging from $2.20 \pm$ 0.19 (S4 Carum copticum) to $6.7 \pm 0.16$ ( $\mathrm{S}_{6} \mathrm{NS}$ ) shown in table 2. Among the experimental groups, the gastric acid stimulated by Carum copticum had the strongest acidic $\mathrm{pH}$ and stimulated by Cuminum cyminum seed extract had the weakest $\mathrm{pH}$ compared to the control. The results showed no statistical significance $(\mathrm{P}<0.05)$ compared to control.

The pHs of the gastric acid secretions were all acidic, ranging from $3.55 \pm 0.38$ (S4) to weakly acidic $6.70 \pm 0.16$ in control group. Although , there were variation among the rats, the results were statically significant. In spite of the fact the gastric juice $\mathrm{pHs}$ are reported to be between 1.8-3 (Guyton and the hall, 2006) the weaker pHs observed in the presents study may not be unconnected with the thrice, $1.5 \mathrm{ml}$ of normal saline used in washing the gastric content before start of gastric perfusion. as described by Vasudevan et al., (2000); perhaps, washing of gastric content with smaller volumes of a recommended external liquid much affect the $\mathrm{pH}$ much less. There appeared to be a seemingly strong correlation between $\mathrm{pH}$ of gastric juices and GAS with $\mathrm{S}_{3} \mathrm{~S}_{4}$ of Carum copticum and Cuminum Cyminum. Fried seed extracts of Carum copticum and Cuminum Cyminum proved the presence of acetylcholine and choline (Devasankaraiah et al., 1974 and Haranath etal., 1987) and consequently elicited the stimulation of GAS with highest $\mathrm{pH}$ values. Similar finding with dietary spices on gastric acid secretion in wistar rats reported (Vasudevan, et al., ${ }^{(10)}$ 2000; Patel and Srinivasan, 2001; 2004, Ikwebe Joseph, et al., 2017.) 
Table 1: Acid content (mean [SEM]) in 15 min samples of gastric perfusate with normal saline and with fried spice extracts

\begin{tabular}{|c|c|c|c|c|c|c|c|}
\hline \multicolumn{8}{|c|}{ Gastric acid content mean SEM mEq/lit } \\
\hline \multirow[b]{2}{*}{ Test substance } & \multirow{2}{*}{$\begin{array}{c}\text { No. of } \\
\text { animals }\end{array}$} & $\mathrm{S}_{1}$ & $\mathrm{~S}_{2}$ & $\mathrm{~S}_{3}$ & $\mathrm{~S}_{4}$ & $\mathrm{~S}_{5}$ & $\mathrm{~S}_{6}$ \\
\hline & & Min. -15 & 30 & 45 & 60 & 75 & 90 \\
\hline Normal Saline & 6 & $0.234 \pm 0.0085$ & $0.263 \pm 0.017$ & $0.303 * * * \pm 0.017$ & $0.303 \pm 0.0189$ & $\begin{array}{c}0.275 \\
\pm 0.012 \\
\end{array}$ & $\begin{array}{l}0.214 \pm \\
0.0874\end{array}$ \\
\hline $\begin{array}{l}\text { Carum } \\
\text { capticum } \\
(\mathrm{CCE})\end{array}$ & 6 & $0.663 \pm 0.037$ & $0.821 \pm 0.040$ & $1.235 * * \pm 0.155$ & $\begin{array}{c}1.279 \\
\pm 0.089\end{array}$ & $\begin{array}{c}1.605 \\
\pm 0.061\end{array}$ & $\begin{array}{l}1.308 * * \\
\pm 0.0576\end{array}$ \\
\hline $\begin{array}{l}\% \text { GAS over } \\
\text { control }\end{array}$ & 6 & 35 & 34 & 41 & 42 & 68 & 61 \\
\hline $\begin{array}{l}\text { Cuminum } \\
\text { cyminum } \\
(\text { CUE) }\end{array}$ & 6 & $0.662 \pm 0.241$ & $0.846 \pm 0.033$ & $\begin{array}{c}1.196 * \\
\pm 0.063\end{array}$ & $\begin{array}{c}1.196 * \\
\pm 0.048\end{array}$ & $\begin{array}{c}0.520 \pm \\
0.061\end{array}$ & $\begin{array}{c}0.366 * * \\
\pm 0.051\end{array}$ \\
\hline $\begin{array}{l}\% \text { GAS over } \\
\text { control }\end{array}$ & 6 & 19 & 33 & 39 & 40 & 22 & 17 \\
\hline
\end{tabular}

$\mathrm{P}^{*}<0.05, * *<0.02, * * *<0.005,++<0.001$ for $\mathrm{S}_{3}$ compared to $\mathrm{S}_{1}$ or $\mathrm{S}_{3}-\mathrm{S}_{1}, \mathrm{~S}_{4}$ compared to $\mathrm{S}_{6}$ or $\mathrm{S}_{4}-\mathrm{S}_{6}$

GAS - Gastric Acid Secretion

Table 2: $\mathrm{pH}$ of gastric perfusate with normal saline and with fried spices extracts.

\begin{tabular}{|l|c|c|c|c|c|c|c|}
\hline \multicolumn{7}{|l|}{ perfusate } & $\begin{array}{c}\text { Overnight } \\
\text { fasting } \\
\text { samples }\end{array}$ \\
\hline Nost substance & $\mathrm{S}_{1}$ & $\mathrm{~S}_{2}$ & $\mathrm{~S}_{3}$ & $\mathrm{~S}_{4}$ & $\mathrm{~S}_{5}$ & $\mathrm{~S}_{6}$ \\
\hline $\begin{array}{l}\text { Carum copticum } \\
\text { (CCE) }\end{array}$ & $4.01 \pm 0.28$ & $5.85 \pm 0.21$ & $5.5 \pm 0.12$ & $4.80 \pm 0.12$ & $3.55 \pm 0.38$ & $6.10 \pm 0.29$ & $6.70 \pm 0.16$ \\
\hline $\begin{array}{l}\text { Cuminum } \\
\text { Cyminum(CUE) }\end{array}$ & $4.60 \pm 0.37$ & $5.2 \pm 0.58$ & $6.5 \pm 0.12$ & $4.21 \pm 0.25$ & $4.35 \pm 0.01$ & $5.48 \pm 0.29$ & $6.0 \pm 0.32$ \\
\hline
\end{tabular}

\section{Conclusion}

Dietry spices are a major component of diets around the world especially in India and Asia. The present study showed that aqueous extracts of fried seeds of Carum copticum and Cuminum Cyminum significantly increases gastric acid secretion and $\mathrm{pH}$ of gastric juices. Further studies of recommended to clarify the true mechanism of the effect.

\section{Acknowledgement}

The authors are grateful to the Dean, Faculty of Medicine, Dr. P.S.R.K. Haranath, former professor of Pharmacology, for his encouragement, Dr. S. Sethupathy, Professor of Biochemistry, Rajah Muthiah Medical College, and Dr. G. Jagadeesan, Professor and Head, Department of Zoology, Annamalai University, for providing necessary facilities.

\section{References}

1. Almofleh, I.A, (2010), Spices, herbal xenobiotics and the stomach; Friends or foes? world Journal of Gastroenterology, 16 (22): 2710-2719.

2. Devasankaraiah, G; Hanin, I; Haranath, P.S.R.K. and Ramanamurthy, P.S.V. (1974). Cholinomimetic effect of aqueous extracts from Carum copticum seeds. Br. J. Pharmacol. 52; p.613-614.

3. Ghosh, M.N. and Schild, H.o. (1958) continuous recording of acid secretion in the rat. Br. J. Pharmacol. 13;p.54-61.

4. Haranath, P.S.R.K.,; Akther M.H. and sharif, S.I. (1987). Acetylcholine and choline in common spices. Phytotherapy Reasearch 1 ; p. 91-92.

5. Joseph, I., Silsa,T.V, Andefiki, U., Olang, O.J.,(2017) effect of ethanolic extracts of 
selected dietary spices on gastric acid secretion in Wistar rats. Intl. J chemical and Biomedical science.3(4): 32-38.

6. Kirtikar, K.R. and Basu, B.D. (1984). Indian Medicinal plants second edn. 4 volumes. Publishers Bishen Singh Mahendra palsingh, Dehra Dun, India.

7. Lizt, K.I., Ley, J.P., Lider, B., Behrens, M., Stoger, V., Reiner, A, Hochkogler, C.M., Kock, E., Marchiori, A., Hans, J., Widder.S., Krammer, G., Sager, G.J., Somoza, M.M., Meyerhof. W., Somoza, V., (2017), Caffeine induces gastric acid secretion via bitter taste signaling in gastric parietal cells. PNAS : E6260 E6269. doi/10.1073/Pnas.1703728114.

8. Nadkarni, A.K. (1976) Dr. K.M. Nadakarni's Indian Materia Media. Popular Book depot, Bombay, India; 269410.

9. Reynolds. E/F/ (1989), Martindale. The extra pharmacopeia, 29 ${ }^{\text {th }}$ Edn. The pharmaceutical press, London, U.K.

10. Vasudevan, K.; Vembar, S,; Veeraraghavan K. and Haranth, P.S.R.K. (2000), Influence of intragastric perfusion of aqueous spice extracts on acid secretion in anesthetized albino rats. Indian Journal of Gastroenterology 19; p. 53 - 56. 